Research Article

\title{
Association of XRCC1 Arg399GIn and Tp53 Arg72Pro polymorphisms and increased risk of uterine leiomyoma - A case-control study
}

\author{
Minoo Yaghmaei ${ }^{1}$, Saeedeh Salimi ${ }^{2,3}$, Lida Namazi ${ }^{4}$ and Farzaneh Farajian-Mashhadi ${ }^{2,5}$ \\ ${ }^{1}$ Department of Obstetrics and Gynecology, School of Medicine, \\ Shahid Beheshti University of Medical Sciences, Tehran, Iran. \\ ${ }^{2}$ Cellular and Molecular Research Center, Zahedan University of Medical Sciences, Zahedan, Iran. \\ ${ }^{3}$ Department of Clinical Biochemistry, School of Medicine, \\ Zahedan University of Medical Sciences, Zahedan, Iran. \\ ${ }^{4}$ Department of Obstetrics and Gynecology, School of Medicine, Zahedan University of Medical Sciences, \\ Zahedan, Iran. \\ ${ }^{5}$ Department of Pharmacology, School of Medicine, Zahedan University of Medical Sciences, Zahedan, Iran.
}

\begin{abstract}
The aim of present study was to investigate the role of the $X$-ray repair cross-complementing protein1 (XRCC1) and Tumor protein p53 (Tp53) polymorphisms in Uterine Leiomyoma (UL) susceptibility in southeastern Iran. This case control study was performed on 139 women with UL and 149 age, BMI and ethnicity matched healthy women. All women were genotyped for the XRCC1 Arg399GIn, XRCC1 Arg194Trp and Tp53 Arg72Pro polymorphisms. The frequency of Tp53 72 Pro/Pro genotype was significantly higher in UL women compared to controls. The risk of UL was 1.5 fold higher in women with the Pro/Pro genotype (OR, 1.5 [95\% Cl, 1.1 to 2.1], $\mathrm{p}=0.012$ ). Moreover, the frequency of the Pro allele was significantly higher in the UL women. Although the frequency of XRCC1 Arg399GIn genotypes did not significantly differ between UL and control groups before adjusting for age, there was an association between the $X R C C 1 \mathrm{Arg} / \mathrm{Gln}$ genotype and UL after adjusting for age (OR, 1.8 [95\% Cl, 1.1 to 3]). No association was observed between the XRCC1 Arg194Trp polymorphism and UL. The Pro/Pro genotype of Tp53 Arg72Pro polymorphism was associated with UL susceptibility. In addition, the XRCC1 Arg/GIn genotype was associated with increased risk of UL after adjusting for age.
\end{abstract}

Keywords: uterine leiomyoma, Tp53, XRCC1, polymorphism.

Received: February 23, 2015; Accepted: July 12, 2015.

\section{Introduction}

Uterine leiomyoma (UL) is a benign neoplasm of the uterine smooth muscle and is originated from the myometrium. ULs are the most common solid tumors of the uterus and pelvis, afflicting $20-25 \%$ of women (Hoffman et al., 2012), and are a common condition with various complications, such as abnormal uterine hemorrhage, pressure on adjacent viscera, and even negative effects on reproduction (Haney, 2000). UL is more prevalent at younger age and its prevalence differs in various ethnic groups; it is higher among black women compared to whites. Late reproductive age, nulliparity, and obesity are other predisposing factors for this complication (Flake et al., 2003).

Send correspondence to Saeedeh Salimi. Cellular and Molecular Research Center, Zahedan University of Medical Sciences, and Department of Clinical Biochemistry, School of Medicine, Zahedan University of Medical Sciences, Khalije Fars Avenue, Zahedan, Iran. E-mail: sasalimi@yahoo.com.
Estrogen and Progesterone are growth promoters of UL and probably exert their effects through growth factors that are elevated in uterine leiomyoma (Parker, 2007). It has been reported that $40-50 \%$ of women with UL have abnormalities in somatic chromosomes, and the most common observed chromosomal abnormalities are deletions on chromosome 7 , trisomy of chromosome 12 , and translocation between chromosomes 12 and 14. In addition, atypical and large leiomyoma commonly accompanied with chromosomal abnormalities and a positive relationship between cytogenetic anomalies and UL location has been reported. Therefore, genetic factors could play an important role in UL susceptibility (Medikare et al., 2011; Parker, 2007).

Since ULs are monoclonal tumors which arise from uninhibited division of one myometrial cells, cell cycle regulation and DNA repair failure may be the initial events in formation of UL (Jeon et al., 2005). Several studies have evaluated the correlation between different polymorphisms 
in genes encoding cell cycle regulatory proteins and susceptibility to various tumors (Jeon et al., 2005; Salimi et al., 2014a).

Up to now, the Tumor protein 553 (Tp53) gene is considered the best tumor suppressor gene and could be activated in response to several cellular signals leading to cell cycle regulation. When DNA is damaged in a cell, the p53 protein causes apoptosis by cell cycle arrest in G1 phase. The Tp53 gene is located on chromosome 17 and encodes a $53 \mathrm{kDa}$ protein containing 393 amino acids. The Tp53gene has various single nucleotide polymorphisms (SNPs) with probable functional effects. Replacement of Arg (CGC) by Pro (CCC) in the transactivation domain of the p53 protein has been the most studied Tp 53 SNP that could affect tumor suppression activity of this protein (Pietsch et al., 2006; Shu et al., 2007). X-ray repair cross-complementing protein1 (XRCC1) or DNA repair protein XRCC1 has a significant effect on DNA repair. XRCC1 interacts with enzymatic proteins of different stages in DNA strand break repair, such as Poly [ADP-ribose] polymerase 1(PARP-1), Apurinic/apyrimidinic (AP) endonuclease-1, polynucleotide kinase, DNA polymerase-b, and DNA ligase IIIa (Caldecott, 2003). Therefore, XRCC1 polymorphisms that cause amino acid substitutions may alter DNA strand break repair by affecting XRCC1 interaction with other enzymatic proteins (Caldecott, 2003; Jeon et al., 2005; Shen et al., 1998).

There are limited reports about the association between $T p 53$ and $X R C C 1$ polymorphisms and UL susceptibility, with conflicting results. Therefore we aimed to investigate the association between Tp53 Arg72Pro, XRCC1 Arg399Gln and XRCC1 Arg194Trp polymorphisms and uterine leiomyoma women from southeastern Iran.

\section{Material and Methods}

In this study, 139 women with UL in pre-menopause stage who had undergone myomectomy or hysterectomy in Ali-ibn-Abitaleb Hospital, Zahedan, southeastern Iran, were enrolled during 2011-2013. The participants were selected using the convenient sampling method. In all participants, uterine leiomyoma was confirmed pathologically.

One hundred forty nine healthy women, also in premenopause stage, were selected as the control group from women referring for routine yearly check-ups and performing the Pap smear test. Both groups were matched with respect to demographic variables such as age, BMI (Body Mass Index) and ethnicity (Fars or Balouch). The participants in the control group had no evidence of uterine leiomyoma upon sonography or examination. Their Pap smear test was also negative. The exclusion criteria were existence of systemic disease and history of malignancy. All participants were Iranian and gave their informed consent before participating in the study. The protocol of this study was approved by the Ethics Committee of Zahedan University of Medical Sciences and conducted in accordance with the Declaration of Helsiniki.

\section{Genotype analysis}

Genomic DNA was extracted from $2 \mathrm{~mL}$ peripheral blood leukocytes using the salting out phenol chloroform method and stored at $-20{ }^{\circ} \mathrm{C}$ until analysis. Tetra-primer amplification refractory mutation system (ARMS) was performed for detection of XRCC1 Arg399Gln and Arg194Trp polymorphisms, as previously described by (Salimi et al., 2014b).

The analysis of $T p 53$ Arg72Pro polymorphism was carried out using the polymerase chain reaction-restriction fragment length polymorphism (PCR-RFLP) method. The fragment containing Tp53 Arg72Pro SNP was amplified using the following forward and reverse primers: 5'- GTC CCA AGC AAT GGA TGA T -3' and 5'- CAA AAG CCA AGG AAT ACA CG -3', respectively (Cheng et al., 2012). The total volume of the PCR mixture was $25 \mu \mathrm{L}$ and contained $200 \mathrm{ng}$ of genomic DNA, $25 \mathrm{pM}$ of each primer, $0.1 \mathrm{mM}$ of dNTP (Fermentas, Lithuania), $1.5 \mathrm{mM} \mathrm{MgCl}_{2}$, $2.5 \mu \mathrm{L}$ 10x PCR buffer, and $1 \mathrm{U}$ of Taq polymerase (Fermentas, Lithuania). Amplifications were carried out in a Bio-Rad thermal cycler (Bio.Rad, Hercules, CA, USA) using a thermal profile of initial denaturation at $96{ }^{\circ} \mathrm{C}$ for $6 \mathrm{~min}$, followed by 30 cycles at $96^{\circ} \mathrm{C}$ for $30 \mathrm{~s}$, annealing at $61{ }^{\circ} \mathrm{C}$ for $30 \mathrm{~s}$, primer extension at $72^{\circ} \mathrm{C}$ for $60 \mathrm{~s}$, and a final extension step at $72{ }^{\circ} \mathrm{C}$ for $6 \mathrm{~min}$. The $551 \mathrm{bp} \mathrm{PCR} \mathrm{product}$ of the Arg72Pro polymorphism was digested by Bst $\mathrm{U} 1$ (Bsh1236I) restriction enzyme (Fermentas, Lithuania) and was incubated at $37{ }^{\circ} \mathrm{C}$ overnight. Post-digestion PCR products were identified by electrophoresis on $2.5 \%$ agarose gels. The G (Arg) allele had one Bst $\mathrm{U} 1$ cleavage site and was digested to 443 and $108 \mathrm{bp}$ fragments; whereas the C (Pro) allele had no cleavage site and produced a single 551 bp fragment only.

\section{Statistical analysis}

Statistical analyses were performed using Statistical Package for Social Sciences (SPSS) version 17 (SPSS Inc., Chicago, IL, USA). The frequency of genotypes and alleles was compared between UL women and controls using the Chi-square or Fisher's exact tests. Student's $t$-test was used for comparison of quantitative variables. A $p<0.05$ was considered as statistically significant. The association between SNPs and UL were estimated by calculating the odds ratio (OR) and its $95 \%$ confidence interval (CI). Linkage disequilibrium (LD) was analyzed using CubeX software (Kumazaki et al., 2002). The independent effect of each risk polymorphism and haplotypes on UL was assessed by Logistic regression analysis. 


\section{Results}

The demographic characteristics of the UL women and the control group are shown in Table 1.

We found no significant differences in age, BMI, parity and marital status between the two groups. There were also no significant differences in menstrual histories, such as age of menarche, duration of menses, and menstrual cy- cle among UL women and controls. However, the frequency of bleeding and pain was significantly higher in women with UL $(\mathrm{p}<0.0001)$.

The allelic and genotypic frequencies of the Tp53 Arg72Pro, XRCC1 Arg399Gln and XRCC1 Arg194Trp polymorphisms in UL women and controls are shown in Table 2. All loci conformed to the Hardy-Weinberg equilibrium ( $\mathrm{p}>0.05$ ). The frequencies of Tp53 72Arg/Arg,

Table 1 - Clinical and demographic characteristics of the uterine leiomyoma women and control group.

\begin{tabular}{lccc}
\hline & UL women $(\mathrm{n}=139)$ & Controls $(\mathrm{n}=149)$ & $\mathrm{p}$-value \\
\hline Age (years) & $38.4 \pm 9.7$ & $37.3 \pm 6.7$ & NS \\
Marriage status, $\mathrm{n}(\%)$ & $134(96.4)$ & $145(97.3)$ & $\mathrm{NS}$ \\
BMI $\left(\mathrm{kg} / \mathrm{m}^{2}\right)$ & $25.0 \pm 5.8$ & $25.5 \pm 5$ & $\mathrm{NS}$ \\
Parity(n) & $3.4 \pm 2.6$ & $3.9 \pm 2.3$ & $\mathrm{NS}$ \\
Age of menarche (years) & $13.6 \pm 1.1$ & $13.3 \pm 1.5$ & $\mathrm{NS}$ \\
Duration of menses (days) & $6.1 \pm 1.6$ & $5.6 \pm 1.5$ & $\mathrm{NS}$ \\
Menstrual cycle (days) & $28.6 \pm 2.2$ & $28.0 \pm 2.6$ & $\mathrm{NS}$ \\
Bleeding, $\mathrm{n}(\%)$ & $82(59)$ & $5(3.4)$ & 0.0001 \\
Pain, $\mathrm{n}(\%)$ & $41(30)$ & $11(7.4)$ & 0.0001 \\
\hline
\end{tabular}

Table 2 - Genotypic and allelic frequencies of Tp53 Arg/Pro and XRCC1 Arg399Gln polymorphisms in uterine leiomyoma women and control group.

\begin{tabular}{|c|c|c|c|c|c|c|}
\hline & UL women $(n=139)$ & controls $(n=149)$ & $\mathrm{p}$ value & OR $(95 \% \mathrm{CI})$ & $\mathrm{p}$ value & OR $(95 \% \mathrm{CI})^{*}$ \\
\hline \multicolumn{7}{|l|}{ Tp53 (Arg72Pro) } \\
\hline Arg/Arg, n (\%) & $36(26)$ & $53(36)$ & & 1 & & 1 \\
\hline Arg/Pro, n (\%) & $65(47)$ & $72(48)$ & 0.3 & $1.3(0.8-2.3)$ & 0.3 & $1.3(0.8-2.3)$ \\
\hline Pro/Pro, n (\%) & $38(27)$ & $24(16)$ & 0.012 & $1.5(1.1-2.1)$ & 0.014 & $1.5(1.1-2.1)$ \\
\hline \multicolumn{7}{|l|}{ Allele } \\
\hline Arg, n (\%) & $137(49.3)$ & $178(59.7)$ & & 1 & & \\
\hline Pro, n (\%) & $141(50.7)$ & $120(40.3)$ & 0.012 & $1.5(1.1-2.1)$ & & \\
\hline \multicolumn{7}{|l|}{$\begin{array}{l}\text { XRCC1 } \\
(\text { Arg399Gln) }\end{array}$} \\
\hline Arg/Arg, n (\%) & $63(45.3)$ & $85(57)$ & & 1 & & 1 \\
\hline Arg/Gln, n(\%) & $60(43.2)$ & $50(34)$ & 0.06 & $1.6(1-2.7)$ & 0.03 & $1.8(1.1-3)$ \\
\hline $\mathrm{Gln} / \mathrm{G} \ln , \mathrm{n}(\%)$ & $16(11.5)$ & $14(9)$ & 0.3 & $1.2(0.8-1.8)$ & 0.2 & $1.3(0.9-1.9)$ \\
\hline \multicolumn{7}{|l|}{ Allele } \\
\hline Arg, n (\%) & $186(67)$ & $220(74)$ & & 1 & & \\
\hline Gln, n (\%) & $92(33)$ & $78(26)$ & 0.07 & $1.4(1-2)$ & & \\
\hline \multicolumn{7}{|l|}{$\begin{array}{l}\text { XRCC1 } \\
\text { (Arg394Trp) }\end{array}$} \\
\hline $\operatorname{Arg} / \operatorname{Arg}, \mathrm{n}(\%)$ & $85(61)$ & $94(63)$ & & 1 & & 1 \\
\hline Arg/Trp, n (\%) & $51(37)$ & $51(34)$ & 0.7 & $1.1(0.7-1.8)$ & 0.7 & $1.1(0.7-1.8)$ \\
\hline Trp/Trp, n (\%) & $3(2)$ & $4(3)$ & 0.8 & $0.9(0.4-2)$ & 0.8 & $0.9(0.4-1.9)$ \\
\hline \multicolumn{7}{|l|}{ Allele } \\
\hline Arg, n (\%) & $221(79.5)$ & $239(80)$ & & 1 & & \\
\hline Trp, n (\%) & $57(20.5)$ & $59(20)$ & 0.84 & $1.1(0.7-1.6)$ & & \\
\hline
\end{tabular}

*Adjusted for age. 
Arg/Pro and Pro/Pro genotypes were 26, 47 and $27 \%$ in the UL women and 36,48 and $16 \%$ in control group, respectively. Although the frequency of the heterozygous Arg/Pro genotype was similar in the two groups, the frequency of the homozygous Pro/Pro genotype was significantly higher in UL women compared to the control group. The risk of leiomyoma was 1.5 fold greater in Pro/Pro genotype women compared to the Arg/Arg genotype (OR, 1.5 [95\% CI, 1.1 to 2.1], $\mathrm{p}=0.012$ ). Moreover, the frequency of the Pro allele was significantly higher in UL women compared to controls $(51 \%$ vs. $40 \%, \mathrm{p}=0.012)$. Although there was no association between the $\mathrm{Arg} / \mathrm{Gln}$ genotype of the XRCC1 Arg399Gln polymorphism and UL before adjusting for age, we observed a significant association between this genotype and UL susceptibility after adjusting for age. There was no association between XRCC1 Arg194Trp polymorphism and UL.

Four haplotypes of the XRCC1 Arg399Gln and XRCC1 Arg194Trp polymorphisms with two-alleles of each polymorphism are shown in Table 3. There were no differences in haplotype frequency between UL patients and controls as well. Linkage disequilibrium calculated for $X R C C 1$ gene polymorphisms (rs1799782 and rs25484) were $\mathrm{D}^{\prime}=0.58, \mathrm{r}^{2}=0.2$ in UL and $\mathrm{D}^{\prime}=0.55, \mathrm{r}^{2}=0.2$ in control women.

\section{Discussion}

The present study revealed that the Pro/Pro genotype of the $T p 53 \mathrm{Arg} 72$ Pro polymorphism was associated with higher risk of uterine leiomyoma compared to the Arg/Arg genotype, and the frequency of the Pro allele was significantly higher in UL women. Although there was no association between the XRCC1 Arg/Gln genotype and UL before adjusting for age, we found an association between Arg/Gln genotype and UL after adjusting for age. In addition XRCC1 Arg194Trp was not correlated with UL susceptibility.

Although uterine leiomyomas are frequently seen in the uterus, data about its growth and development have rarely been reported. Compared to other tumors, alteration in various genetic targets may lead to dysregulation of smooth muscle cells leading to the typical phenotype of UL. Other than somatic mutations of genes which can lead to proliferation and apoptosis of normal myometrium, the interaction between sexual hormones and growth factors has a crucial role in transforming myometrial smooth muscle cells to leiomyoma (Gittenberger-de Groot et al., 1999; Hirst et al., 2000).

Uterine leiomyoma is pathophysiologically very similar to other fibrotic diseases, including vascular restenosis, atherosclerosis, and interstitial fibrosis that are developed in the kidney, pancreas and liver. It was also proposed that various injuries to the myometrium, including hypoxia, might be important in UL formation (Mesquita et al., 2010).

Considering the role of $\mathrm{p} 53$ and $\mathrm{XRCC} 1$ in cell cycle and repair regulation, we evaluated the possible effects of XRCC1 Arg399Gln, XRCC1 Arg194Trp and Tp53 Arg72Pro polymorphisms on the susceptibility of UL. There are several studies with controversial results about the association between $T p 53$ gene polymorphisms and UL, however in the majority of the studies there was no correlation between Tp53 Arg72Pro polymorphism and UL susceptibility.

Previous results (Hall et al., 1997) showed that although 6 out of 23 patients with leiomyosarcomas exhibited Tp53 abnormalities, no patient with leiomyoma had a Tp53 abnormality. Moreover when Patrakis et al. (2003) analyzed exons 5-8 of the Tp53 gene in UL women, they concluded that the dysregulation of this gene is not required for leiomyoma development. Hsieh et al. (2004) showed that the Tp53 Arg72Pro polymorphism is not a risk factor for UL in Taiwanese women. Similar to the results of our study, carriage of the Tp53 codon 72 polymorphism could be associated with UL susceptibility in a Caucasian population (Germany) and may contribute to the pathology of leiomyoma (Denschlag et al., 2005). In another study on several polymorphisms in the promoter region of the $T p 53$ gene, a -216C and a -103G SNP were found to be associated with the development of UL (Hsieh et al., 2007).

There are a few studies about the association between the XRCC1 Arg399Gln and XRCC1 Arg194Trp polymorphisms and UL. Jeon et al. (2005) reported an association between the XRCC1 399Gln allele and UL after adjusting for age, parity, menarche age and body mass index in Korean women. They observed that the incidence of UL was 6.8 fold higher in individuals with the Arg/Gln genotype compared to the Arg/Arg genotype (Jeon et al., 2005). Similarly, we found an association between the Arg/Gln genotype and UL after adjusting for age. In addition Yang et al.

Table 3 - Haplotypes frequency of XRCC1 Arg399Gln and Arg194Trp polymorphisms in uterine leiomyoma women and control group.

\begin{tabular}{lccccc}
\hline XRCC1 Arg399Gln & XRCC1 Arg194Trp & UL women $(\mathrm{n}=139)$ & controls (n=149) & p value & OR (95\% CI) \\
\hline Arg & Arg & $64 \%$ & $67.6 \%$ & & 1 \\
Arg & Trp & $5.8 \%$ & $6.8 \%$ & 0.8 & $0.9(0.3-2.4)$ \\
Gln & Arg & $15.8 \%$ & $12.2 \%$ & 0.4 & $1.2(0.8-1.7)$ \\
Gln & Trp & $14.4 \%$ & $13.5 \%$ & 0.7 & $1(0.8-1.3)$ \\
\hline
\end{tabular}


showed the correlation between Arg280His but not Arg399Gln and Arg194Trp polymorphisms and UL in China(Yang et al., 2010) In another study, Hsieh et al. did not observe any association between Arg399Gln and UL in Taiwan(Hsieh et al., 2009). There are reports showing that the $399 \mathrm{Gln}$ allele might be associated with more DNA adduct and sister chromatid exchange, as well as mutations. Such findings may, at least in theory, be associated with higher risk of malignancy (Duell et al., 2000; Lunn et al., 1999).

The current study suffers from some limitations; for example low sample size which might affect the results, environmental conditions and different ethnic groups living in southeastern Iran. In addition, if it would have been possible to perform this study on both myomatous and intact tissues the results would have been be more conclusive.

In conclusion, our results show that the Pro/Pro genotype and Pro allele of Tp53 Arg72Pro polymorphism are probable risk factors for uterine leiomyoma. Although no association was seen between the XRCC1 Arg399Gln polymorphism and uterine leiomyoma susceptibility before adjusting for age, a significant relationship was observed after adjusting for age.

\section{Acknowledgments}

This work is based on the Residency's Thesis (Dr. Lida Namazi, Number 2161) at Zahedan University of Medical Sciences. The authors thank the Zahedan Deputy of Research Affairs for funding this project.

\section{References}

Caldecott KW (2003) XRCC1 and DNA strand break repair. DNA Repair 2:955-969.

Cheng Z, Wang W, Song YN, Kang Y and Xia J.(2012) hOGG1, p53 genes, and smoking interactions are associated with the development of lung cancer. Asian Pac J Cancer Prev 13:1803-1808.

Denschlag D, Bettendorf H, Watermann D, Keck C, Tempfer C,and Pietrowski D (2005) Polymorphism of the p53 tumor suppressor gene is associated with susceptibility to uterine leiomyoma. Fertil Steril 84:162-166.

Duell EJ, Wiencke JK, Cheng TJ, Varkonyi A, Zuo ZF, Ashok TD, Mark EJ, Wain JC, Christiani DC and Kelsey KT (2000) Polymorphisms in the DNA repair genes XRCC1 and ERCC2 and biomarkers of DNA damage in human blood mononuclear cells. Carcinogenesis 21:965-971.

Flake GP, Andersen J and Dixon D (2003) Etiology and pathogenesis of uterine leiomyomas: a review. Environ Health Perspect 111:1037-1054.

Gittenberger-de Groot AC, DeRuiter MC, Bergwerff M and Poelmann RE (1999) Smooth muscle cell origin and its relation to heterogeneity in development and disease. Arterioscler Thromb Vasc Biol 19:1589-1594.

Gu Y, Lewis DF and Wang Y (2008) Placental productions and expressions of soluble endoglin, soluble fms-like tyrosine kinase receptor-1, and placental growth factor in normal and preeclamptic pregnancies. J Clin Endocrinol Metab 93:260-266.

Hall KL, Teneriello MG, Taylor RR, Lemon S, Ebina M, Linnoila RI, Norris JH, Park RC and Birrer MJ (1997). Analysis of Ki-ras, p53, and MDM2 genes in uterine leiomyomas and leiomyosarcomas. Gynecol Oncol 65:330-335.

Haney AF (2000) Clinical decision making regarding leiomyomata: what we need in the next millenium. Environ Health Perspecti 108 Suppl 5:835-839.

Hirst SJ, Twort CH and Lee TH (2000). Differential effects of extracellular matrix proteins on human airway smooth muscle cell proliferation and phenotype. Am J Respir Cell Mol Biol 23:335-344.

Hoffman BLS, Schorge JO, Schaffer JI, Halvorson LM, Bradshaw KD and Cunningham FG (2012) Williams Gynecology. $2^{\text {nd }}$ edition. McGraw Hill, New York, 823 p.

Hsieh YY, Chang CC, Tsai FJ, Lin CC, Yeh LS and Tsai CH (2004) Tumor necrosis factor-alpha-308 promoter and p53 codon 72 gene polymorphisms in women with leiomyomas. Fertil Steril 82 Suppl 3:1177-1181.

Hsieh YY, Wang JP and Lin CS (2007) Four novel single nucleotide polymorphisms within the promoter region of $\mathrm{p} 53$ gene and their associations with uterine leiomyoma. Mol Reprod Dev 74:815-820.

Jauniaux E, Poston L and Burton GJ (2006) Placental-related diseases of pregnancy: involvement of oxidative stress and implications in human evolution. Hum Reprod Update 12:747-755.

Jeon YT, Kim JW, Park NH, Song YS, Kang SB and Lee HP (2005) DNA repair gene XRCC1 Arg399Gln polymorphism is associated with increased risk of uterine leiomyoma. Hum Reprod 20:1586-1589.

Kumazaki K, Nakayama M, Suehara N and Wada Y (2002) Expression of vascular endothelial growth factor, placental growth factor, and their receptors Flt-1 and KDR in human placenta under pathologic conditions. Hum Pathol 33:1069-1077.

Lunn RM, Langlois RG, Hsieh LL, Thompson CL and Bell DA (1999) XRCC1 polymorphisms: effects on aflatoxin B1DNA adducts and glycophorin A variant frequency. Cancer Res 59:2557-2561.

Medikare V, Kandukuri LR, Ananthapur V, Deenadayal M and Nallari P (2011) The genetic bases of uterine fibroids; a review. J Reprod Infertil 12:181-191.

Mesquita FS, Dyer SN, Heinrich DA, Bulun SE, Marsh EE and Nowak RA (2010) Reactive oxygen species mediate mitogenic growth factor signaling pathways in human leiomyoma smooth muscle cells. Biol Reprod 82:341-351.

Parker WH (2007) Etiology, symptomatology, and diagnosis of uterine myomas. Fertil Steri 87:725-736.

Patrikis MI, Bryan EJ, Thomas NA, Rice GE, Quinn MA, Baker MS and Campbell IG (2003) Mutation analysis of CDP, TP53, and KRAS in uterine leiomyomas. Mol Carcinog 37:61-64.

Pietsch EC, Humbey O and Murphy ME (2006). Polymorphisms in the p53 pathway. Oncogene 25:1602-1611.

Salimi S, Mohammadoo-Khorasani M, Tabatabai E, Sandoughi M, Zakeri Z, and Naghavi A. (2014). XRCC1 Arg399Gln and Arg194Trp polymorphisms and risk of systemic lupus erythematosus in an Iranian population: a pilot study. Biomed Res Int 2014:e492956. 
Salimi S, Hajizadeh A, Khodamian M, Pejman A, Fazeli K and Yaghmaei M (2015) Age-dependent association of MDM2 promoter polymorphisms and uterine leiomyoma in SouthEast Iran: a preliminary report. J Obstetr Gynaecol Res 41:729-734.

Shen MR, Jones IM and Mohrenweiser H (1998) Nonconservative amino acid substitution variants exist at polymorphic frequency in DNA repair genes in healthy humans. Cancer Res 58:604-608.

Shu KX, Li B and Wu LX (2007).The p53 network: p53 and its downstream genes. Colloids Surf B Biointerfaces 55:10-18.

Associate Editor: Mara H. Hutz

License information: This is an open-access article distributed under the terms of the Creative Commons Attribution License (type CC-BY), which permits unrestricted use, distribution and reproduction in any medium, provided the original article is properly cited. 